\title{
INDUCTION OF GENE POOL DIFFERENTIATION IN DROSOPHILA MELANOGASTER
}

\author{
S. Alahiotis and M. Pelecanos \\ Department of Genetics. University of Patras, Patras, Greece
}

\begin{abstract}
The selective effect of the ecological parameter "food medium" upon the gene pool of Drosophila melanogaster was investigated in nine cage populations by estimating the allozyme frequencies of the $a-G p d h$ and $A d h$ loci. The differentiation observed was found to depend dramatically upon the action of the above mentioned environmental factor. Small differences may be mainly attributed to the effect of the differing genetic backgrounds of each gene pool. When the environment was restrictive, a dramatic gene pool differentiation was observed. A discussion is provided bearing upon the observed induction of a process which involves large groups of coadapted genes upon which selection actually acts. Furthermore. the role of nutrition. and especially yeast, was found to have a profound effect upon the observed genetic differentiation of the gene pool of D. melanogaster.
\end{abstract}

Veuf populations en cage ont été utilisées lors d'une étude sur les effets sélectifs du paramètre écologique "nourtiture" sur le pool génique de Drosophila melanogaster. La fréquence des allozymes des locus $a-G p d h$ et $A d h$ a été déterminée, et les différences que l'on a observées semblent fortement dépendre du facteur précité. Les légers écarts sont principalement attribués aux différences fondamentales des divers pools géniques qui présentent des distinctions très importantes en milieu restrictif. La discussion qui suit les resultats suppose l'induction d'un mécanisme impliquant d'importants groupes de genes coadaptés sur lesquels se dirige l'action du processus de sélection. Par ailleurs, la nutrition et surtout la levure semblent agir profondément sur la différenciation génétique des pools de $D$. melanogaster.

[Traduit par le journal]

\section{Introduction}

The study of the genetic structure of populations is one of the approaches to understanding the process of evolution. If one wishes simply to comprehend the evolutionary forces or to control them, it is helpful to evaluate the significance of the effect of certain ecological factors upon gene pool differentiation. Many studies have reported on temporal and geographical genic variations in natural populations associated with specific environmental conditions (for review see Parsons, 1973; Nei. 1975). However. data bearing upon these questions may be more appropriately obtained from laboratory cage populations where conditions may be readily controlled

In view of the above. an attempt was made to observe the reaction of a large gene pool of Drosophila melanogaster to the ecological parameter "food medium " ("poor" food medium - restrictive environment; "rich" food medium - optimum environment). It is well known that yeast is the primary food source of Drosophila (Sang, 1949) and that yeast-culture media are very suitable for Drosophila cultures (Demerec. 1965). Thus, food medium poor in yeast generates a restrictive environment in which the flies live under limiting (competitive) conditions, while food medium rich in yeast defines an optimum (or near optimum) environment with no or little competition (Alahiotis. 1976). This investigation examines the idea that should strong competition for food and living space exist, natural selection will occur causing gene pool differentiation. In order to trace such a possible gene pool-environmental reaction. the allozyme frequencies of $a-G p d h$ (a-Glycerophosphate dehydrogenase) and Adh (alcohol dehydrogenase) were utilised. These two enzyme loci were found to associate nonrandomly with the polymorphic inversions of the second chromosome in the populations examined here (Alahiotis et al., 1976). Hence, they can be considered as markers of large blocks of genes. 


\section{Material and Methods}

In our experiments. nine cage populations were studied for the allozyme frequency changes of two enzyme loci, over 30 generations, under the influence of the ecological factor food medium. Populations $1 \mathrm{~A}$. $1 \mathrm{~B}_{3}, 1 \mathrm{~B}_{4}$, and $2 \mathrm{~A}$ were raised at $25 \pm 0.5^{\circ} \mathrm{C} .43 \pm 4 \% \mathrm{RH}$ (relative humidity) in a poor corn meal-agar-sugar food medium (12.5 g corn meal, $1.8 \mathrm{~g}$ sugar. $1 \mathrm{~g}$ agar per $100 \mathrm{H}_{2} \mathrm{O}$, with $\mathrm{I} \mathrm{ml}$ of diluted living yeast suspension per food vial) to which propionic acid was added. Populations, 1B, $1 \mathbf{B}_{1}, 1 \mathbf{B}_{2}, 2 \mathrm{~B}, 1 \mathrm{~A}_{1}$ were exposed to the same conditions of temperature and relative humidity but raised in a rich dead-yeast-agar-sugar food medium ( $10 \mathrm{~g}$ dead-yeast. $10 \mathrm{~g}$ sugar. $3 \mathrm{~g}$ agar per $100 \mathrm{ml} \mathrm{H}_{2} \mathrm{O}$ ) where again propionic acid was added. Care was taken to have more or less the same amount of medium in all the vials used for the experiments. All these populations were maintained under a $12 \mathrm{~h}$ darklight cycle. During the early generations there was a rapid expansion of population size, which subsequently was regulated according to the kind of food medium on which each population was raised. Thus. the rich food medium populations had produced approximately the same number of flies (about 2.800) while. the poor-food medium population size was about $1.100 \mathrm{flies}$. (For more details see Alahiotis. 1976.)

Populations $1 \mathrm{~B}_{3}, 1 \mathrm{~B}_{4}$ as well as $1 \mathrm{~B}_{1}, 1 \mathrm{~B}_{2}$. were derived from the basic population $1 \mathrm{~B}$ ten generations after the latter originated. The previously mentioned populations were put two-by-two $\left(1 B_{1}-1 B_{2}, 1 B_{3}-1 B_{4}\right)$ under the effect of the food medium (rich-poor food medium). Populations 1A, IB originated from a common gene pool of 600 parents collected from a Cephalonian-Greek natural population. while populations 2A. 2B originated from a Gavros-Achaila-Greek natural population. The above mentioned 600 parents originated from 100 isofemale lines derived from recently collected (summer 1973) individuals (populations were set up 20-30 days after the capture of flies). Six ( 3 virgin females and 3 males) $4-6$ days old individuals were taken from each of the isofemale lines and thus the 300 virgin females and the 300 males gathered were allowed to mate randomly in the cage (IB or 2B). Populations $1 \mathrm{~A}$ and $2 \mathrm{~A}$ were derived by replicating the $1 \mathrm{~B}$ or $2 \mathrm{~B}$ populations respectively. Consequently. we may regard the derived populations of each series, as possessing practically the same gene pool. Moreover, in order to provide more evidence, a complementary experiment was carried out involving a new cage population (the $1 A_{1}$ ) which was produced from the 16 th generation of the lA population.

The populations were maintained in plexiglass cages the dimensions of which were $4 \mathrm{l} \times 41 \times 16 \mathrm{~cm}$, possessing 14 vials each (the dimensions of which were $10 \times 2.5 \mathrm{~cm}$ ). For details see Stern (1972).

In sampling the cages, three or four fresh food vials were placed in the cage. After $24 \mathrm{~h}$ the vials were removed and care was taken to avoid crowding in them. The vials were then placed under the same environmental conditions in which the respective populations were originally maintained, and emerging adults were scored for $a$-Gpdh (E.C.1.1.1.8.) and Adh loci (E.C.1.1.1.1.) genotypes. In order to characterize the enzyme genotypes of individual f]ies. starch gel electrophoresis was carried out at 300 volts. $100 \mathrm{~mA}$, for about one hour. using $0.5 \mathrm{M}$ Tris versene-borate buffer pH 8.0 (Shaw and Prasad. 1970). Gells were sliced horizontally: the lower half was stained according to the method of Shaw and Prasad (1970) for a-Gpdh. while the upper half was stained for $A d h$ using the method of Johnson and Denniston (1964).

\section{Results}

Our findings are presented in four tables and four figures. In all cage populations studied, two allozymes for each locus were found. Initial allozyme frequencies used were the frequencies found in the two aforementioned natural Southern Greek populations.

As shown in Table I, the allozyme frequencies of the $a-G p d h$ and $A d h$ loci remain the same over 30 generations for the rich food medium populations $\left(1 \mathrm{~B}, 1 \mathrm{~B}_{1}, 1 \mathrm{~B}_{2}, 2 \mathrm{~B}\right)$ with a slight difference as regards to the $A_{d h}{ }^{F}$ frequency in population $1 B_{1}$ which was contaminated with mites for some generations.

In contrast, a dramatic change was observed in the allozyme frequencies of the $a-G p d h$ and $A d h$ loci for the poor medium populations over 30 generations (Table II). The fast allozyme of the $a-G p d h$ locus revealed an increase in its frequency for all 
TABLE I

Frequency changes in $a-G p d h^{F}$ and $A d h^{\mathrm{F}}$ in $1 \mathrm{~B}, 1 \mathrm{~B}_{1}, 1 \mathrm{~B}_{2} .2 \mathrm{~B}$ cage populations (rich food medium)

\begin{tabular}{|c|c|c|c|c|c|c|}
\hline \multicolumn{7}{|c|}{ Population IB } \\
\hline \multicolumn{4}{|c|}{$a \cdot G p d h^{\mathrm{F}}$} & \multicolumn{3}{|c|}{$A d h^{\mathrm{F}}$} \\
\hline Generation & Frequency & $\begin{array}{c}\text { Sample } \\
\text { size* }\end{array}$ & $S E * *$ & Frequency & $\begin{array}{l}\text { Sample } \\
\text { size }\end{array}$ & SE \\
\hline 1 & 0.5458 & 240 & 0.032 & 0.8945 & 218 & 0.021 \\
\hline 5 & 0.5957 & 188 & 0.036 & 0.9279 & 222 & 0.017 \\
\hline 10 & 0.6231 & 260 & 0.030 & 0.9375 & 272 & 0.015 \\
\hline 13 & 0.6392 & 316 & 0.027 & 0.8829 & 316 & 0.018 \\
\hline 17 & 0.6154 & 182 & 0.036 & 0.8846 & 182 & 0.024 \\
\hline 19 & 0.5753 & 186 & 0.036 & 0.9301 & 186 & 0.019 \\
\hline 21 & 0.5833 & 120 & 0.045 & 0.9083 & 120 & 0.026 \\
\hline 25 & 0.6000 & 230 & 0.032 & 0.8957 & 230 & 0.020 \\
\hline 30 & 0.6067 & 178 & 0.037 & 0.9101 & 178 & 0.021 \\
\hline \multicolumn{7}{|c|}{ Population $1 \mathrm{~B}_{1}$} \\
\hline 10 & 0.6231 & 260 & 0.030 & 0.9375 & 272 & 0.015 \\
\hline 11 & 0.5707 & 184 & 0.036 & 0.9185 & 184 & 0.020 \\
\hline 13 & $0.63+4$ & 186 & 0.035 & 0.8656 & 186 & 0.025 \\
\hline 16 & 0.5833 & 120 & 0.045 & 0.8583 & 120 & 0.032 \\
\hline 23 & 0.6504 & 226 & 0.032 & 0.8142 & 226 & 0.026 \\
\hline \multicolumn{7}{|c|}{ Population $1 \mathrm{~B}_{2}$} \\
\hline 10 & 0.6231 & 260 & 0.030 & 0.9375 & 272 & 0.015 \\
\hline 11 & 0.5833 & 192 & 0.036 & 0.9479 & 192 & 0.016 \\
\hline 13 & 0.5941 & 170 & 0.038 & 0.8647 & 170 & 0.026 \\
\hline 16 & 0.6846 & 130 & 0.041 & 0.8385 & 130 & 0.032 \\
\hline 23 & 0.6696 & 224 & 0.031 & 0.8616 & 224 & 0.023 \\
\hline 30 & 0.6897 & 174 & 0.035 & 0.9368 & 174 & 0.015 \\
\hline \multicolumn{7}{|c|}{ Population 2B } \\
\hline 1 & 0.5663 & 196 & 0.035 & 0.9490 & 196 & 0.016 \\
\hline 5 & 0.4531 & 192 & 0.036 & 0.9688 & 192 & 0.013 \\
\hline 10 & 0.5562 & 160 & 0.039 & 0.9833 & 180 & 0.009 \\
\hline 14 & 0.5000 & 232 & 0.033 & 0.9700 & 232 & 0.011 \\
\hline 15 & 0.6373 & 102 & 0.048 & 0.9706 & 102 & 0.017 \\
\hline 20 & 0.5246 & 122 & 0.045 & 0.9426 & 122 & 0.021 \\
\hline 24 & 0.6842 & 224 & 0.031 & 0.8772 & 224 & 0.022 \\
\hline 29 & 0.5741 & 182 & 0.039 & 0.8944 & 180 & 0.023 \\
\hline
\end{tabular}

*The total number of chromosomes scored (see Tables I. II. III. IV).

**SE = Standard Error (see also Tables II, III).

populations studied while the $A d h \mathrm{~F}_{1}$ allozyme exhibited a decrease in its frequency for all populations studied. It seems that strong directional selection was operating throughout the duration of the experiment. In some cases (population 2A) an elimination of one allele occurs.

Figures 1-4 illustrate in a graphic way those of our findings which we considered to be of great interest. Dramatic changes are observed in allozyme frequencies when the populations are under competitive conditions (poor food medium population), whereas these frequencies remain stable under rich food conditions. In addition, good evidence for the effect of the "food medium" parameter upon allozyme frequency differentiation is demonstrated by cage population $1 \mathrm{~A}_{1}$. In this case we observed (Table III; Figs 1,2) a dramatic reversal, in the direction of allozyme frequencies for both loci when the population is treated first in the poor food medium (population $1 \mathrm{~A}$ ) and then in the rich one (population $1 A_{1}$ ). After a few generations the new frequencies tend to approach 
TABLE II

Frequency changes in $a-G p d h^{\mathrm{F}}$ and $A d h^{F}$ in $1 \mathrm{~A}, 1 \mathrm{~B}_{3}, 1 \mathrm{~B}_{4}, 2 \mathrm{~A}$ cage populations (poor food medium)

\begin{tabular}{|c|c|c|c|c|c|c|}
\hline \multicolumn{7}{|c|}{ Population IA } \\
\hline \multicolumn{4}{|c|}{$a-G p d h^{F}$} & \multicolumn{3}{|c|}{$A d h^{\mathrm{F}}$} \\
\hline Generation & Frequency & $\begin{array}{l}\text { Sample } \\
\text { size }\end{array}$ & $\mathrm{SE}$ & Frequency & $\begin{array}{c}\text { Sample } \\
\text { size }\end{array}$ & SE \\
\hline 1 & 0.5458 & 240 & 0.032 & 0.8945 & 218 & 0.021 \\
\hline 5 & 0.7674 & 172 & 0.032 & 0.5594 & 202 & 0.035 \\
\hline 10 & 0.8275 & 342 & 0.020 & 0.4770 & 348 & 0.027 \\
\hline 14 & 0.9062 & 416 & 0.014 & 0.2260 & 416 & 0.020 \\
\hline 15 & 0.9470 & 556 & 0.012 & 0.2032 & 556 & 0.017 \\
\hline 16 & 0.9200 & 118 & 0.025 & 0.1900 & 118 & 0.036 \\
\hline 19 & 0.8817 & 186 & 0.024 & 0.2957 & 186 & 0.033 \\
\hline 21 & 0.9043 & 94 & 0.030 & 0.3085 & 94 & 0.048 \\
\hline 25 & 0.9558 & 226 & 0.014 & 0.5973 & 226 & 0.033 \\
\hline 26 & 0.9900 & 150 & 0.008 & 0.5400 & 150 & 0.041 \\
\hline 30 & 0.9943 & 174 & 0.006 & 0.5057 & 174 & 0.038 \\
\hline \multicolumn{7}{|c|}{ Population $\mathbf{1 B}_{3}$} \\
\hline 10 & 0.6231 & 260 & 0.030 & 0.9375 & 272 & 0.015 \\
\hline 11 & 0.6548 & 168 & 0.037 & 0.8750 & 168 & 0.026 \\
\hline 13 & 0.5885 & 192 & 0.036 & 0.8854 & 192 & 0.023 \\
\hline 16 & 0.5914 & 186 & 0.036 & 0.9086 & 186 & 0.021 \\
\hline 19 & 0.7448 & 192 & 0.031 & 0.9010 & 192 & 0.022 \\
\hline 21 & 0.8193 & 238 & 0.025 & 0.5672 & 238 & 0.032 \\
\hline 26 & 0.9152 & 224 & 0.019 & 0.5893 & 224 & 0.033 \\
\hline 30 & 0.9444 & 180 & 0.017 & 0.5778 & 180 & 0.039 \\
\hline \multicolumn{7}{|c|}{ Population $1 \mathrm{~B}_{\mathbf{4}}$} \\
\hline 10 & 0.6231 & 260 & 0.030 & 0.9375 & 272 & 0.015 \\
\hline 11 & 0.5667 & 180 & 0.037 & 0.8722 & 180 & 0.025 \\
\hline 13 & 0.6139 & 202 & 0.034 & 0.8663 & 202 & 0.024 \\
\hline 16 & 0.6827 & 208 & 0.032 & 0.6160 & 208 & 0.034 \\
\hline 19 & 0.7474 & 190 & 0.032 & 0.7421 & 190 & 0.032 \\
\hline 21 & 0.8500 & 260 & 0.022 & 0.5346 & 260 & 0.031 \\
\hline 26 & 0.9444 & 162 & 0.018 & 0.6392 & 158 & 0.038 \\
\hline 30 & 0.9891 & 184 & 0.008 & 0.5761 & 184 & 0.036 \\
\hline \multicolumn{7}{|c|}{ Population 2A } \\
\hline 1 & 0.5663 & 196 & 0.035 & 0.9490 & 196 & 0.016 \\
\hline 5 & 0.6310 & 168 & 0.037 & 0.7440 & 168 & 0.034 \\
\hline 10 & 0.8059 & 304 & 0.023 & 0.6833 & 300 & 0.029 \\
\hline 14 & 0.6200 & 660 & 0.019 & 0.7100 & 360 & 0.018 \\
\hline 20 & 0.9022 & 92 & 0.031 & 0.5761 & 92 & 0.052 \\
\hline 24 & 0.9439 & 214 & 0.016 & 0.6028 & 214 & 0.034 \\
\hline 29 & 1.0000 & 138 & - & 0.5435 & 138 & 0.042 \\
\hline
\end{tabular}

those of populations maintained in the rich food medium ( $1 \mathrm{~B}, 1 \mathrm{~B}_{1}, 1 \mathrm{~B}_{2}, 2 \mathrm{~B}$ ). As far as the $A d h^{t}$ frequency differentiation in the 1 A population is concerned, it appears (Fig. 2) that there is a parallel increase of this frequency in both the $1 \mathrm{~A}$ (poor medium) and $1 \mathrm{~A}_{1}$ (rich medium) populations, mainly between the period 20-25 generations. However, this is not true in later generations. Fig. 2 demonstrates an oscillation of the $A d h^{\mathrm{F}}$ frequency in the $1 \mathrm{~A}$ population with a general decrease over the entire 30 generations resulting in a clear frequency differentiation between these populations. The difference in the $A d h^{\mathrm{F}}$ frequency between $1 \mathrm{~A}$ and $1 \mathrm{~A}_{1}$ at the 30 th generation is highly significant $\left(\mathrm{x}_{1}^{2}=9.6658 \mathrm{P}<.01\right.$; according to Workman and Niswander 1970). It is possible that sampling errors or random drift may have been the contributing factors for the 
oscillation observed (unexpectedly high frequency of $A d h^{\mathrm{F}}$ in 20-25 generations) in this population. Moreover. Table II shows clearly that, as a general rule, the $A d h^{\mathrm{F}}$ frequency decreases in every poor medium population throughout the 30 generations examined.

The results of testing for linkage equilibrium between the two loci (by comparing the observed with the expected combinations of the genotypes of $a-G p d h$ and $A d h ; \mathrm{Li}$, 1961) are given in Table IV. and show that these two loci are not generally in linkage equilibrium. Furthermore, in a recent -publication (Alahiotis et al., 1975) we have shown that nonrandom association exists between the allozymes of these loci and the

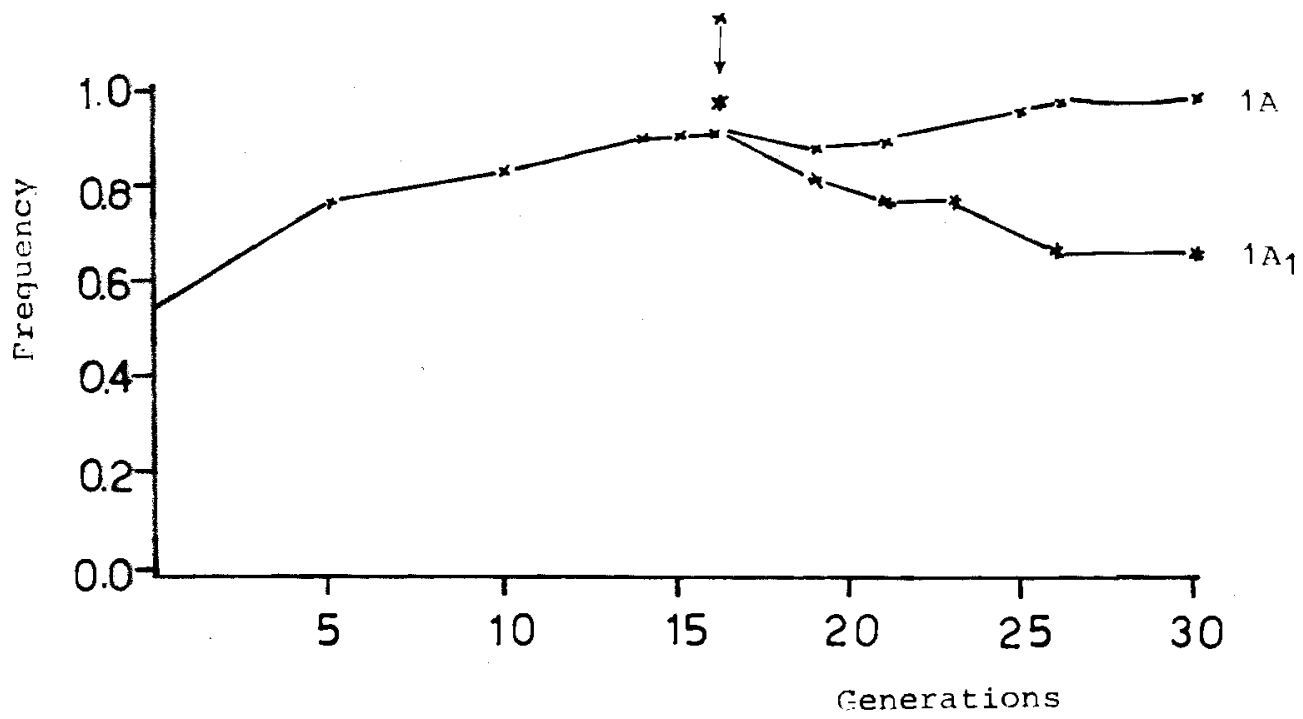

Fig. 1. Changes in frequency of $a-G p d h^{\mathrm{F}}$ allele in $1 \mathrm{~A}(\mathrm{x}), 1 \mathrm{~A}_{1}\left(^{*}\right)$ cage populations (1A-poor food medium: $1 A_{1}$-rich food medium).

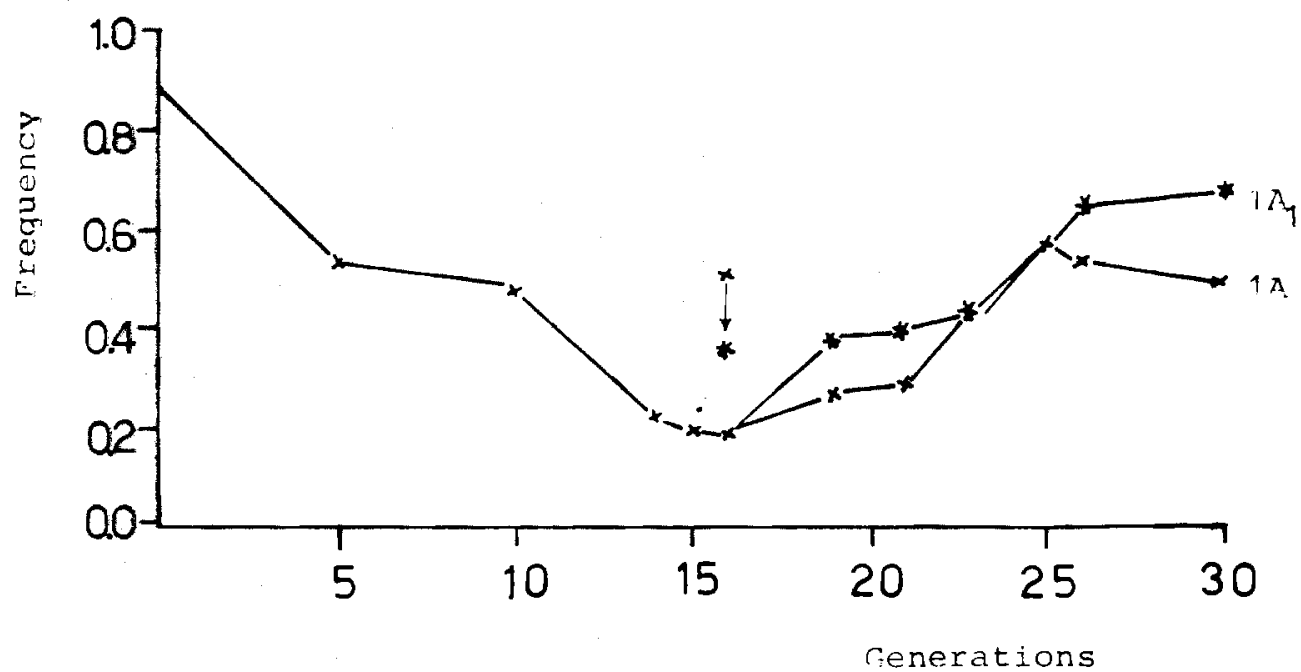

Fig. 2. Changes in frequency of $A d h^{\mathrm{F}}$ allele in the $1 \mathrm{~A}(\mathrm{x}), 1 \mathrm{~A}_{1}\left(^{*}\right)$ cage populations, (1A-poor food medium, $\mid A_{1}$-rich food medium). 
TABLE III

Frequency changes in $a-G p d h^{\mathrm{F}}$ and $A d h^{\mathrm{F}}$ in $1 \mathrm{~A}_{1}$ cage population (rich food medium)

\begin{tabular}{|c|c|c|c|c|c|c|}
\hline \multicolumn{7}{|c|}{ Population $1 A_{1}$} \\
\hline Generation & Frequency & $\begin{array}{l}\text { Sample } \\
\text { size }\end{array}$ & SE & Frequency & $\begin{array}{c}\text { Sample } \\
\text { size }\end{array}$ & $\mathrm{SE}$ \\
\hline 16 & 0.9200 & 118 & 0.025 & 0.1900 & 118 & 0.036 \\
\hline 19 & 0.8253 & 166 & 0.029 & 0.3981 & 216 & 0.033 \\
\hline 21 & 0.7793 & 290 & 0.024 & 0.4000 & 290 & 0.029 \\
\hline 23 & 0.7902 & .224 & 0.027 & 0.4286 & 224 & 0.033 \\
\hline 26 & 0.6699 & 206 & 0.033 & 0.6538 & 182 & 0.035 \\
\hline 30 & 0.6786 & 196 & 0.033 & 0.6667 & 186 & 0.034 \\
\hline
\end{tabular}

$\ln (2 L) 22 D-34 A$ and $\ln (2 R) 52 A-56 F$ inversions, both in cage populations as well as in a natural one. Thus, the existence of linkage disequilibrium between the allozymes of $A d h$ and $a-G p d h$ loci may be considered the result of the presence of these inversions in the population studied. On the other hand, the fact that these two loci belong to two different metabolizing systems (Kojima et al., 1970), decreases the probability of gene interaction between them.

\section{Discussion}

In the present investigation an attempt was made to induce gene pool differentiation under the influence of the environmental factor "poor-rich food

TABLE IV

A test for linkage equilibrium between the $a-G p d h$ and $A d h$ loci in cage populations of Drosophila melanogaster

\begin{tabular}{|c|c|c|c|c|c|c|c|}
\hline \multicolumn{2}{|c|}{$\begin{array}{c}\text { Populations } \\
\text { (generations) }\end{array}$} & \multirow{2}{*}{$\begin{array}{c}\text { Probability } \\
\qquad \frac{(P)}{<.001}\end{array}$} & \multirow{2}{*}{$\begin{array}{c}\begin{array}{c}\text { Sample } \\
\text { size }\end{array} \\
316\end{array}$} & \multicolumn{2}{|c|}{$\begin{array}{c}\text { Populations } \\
\text { (generations) }\end{array}$} & \multirow{2}{*}{$\begin{array}{c}\begin{array}{c}\text { Probability } \\
\text { (P) }\end{array} \\
<.001\end{array}$} & \multirow{2}{*}{$\begin{array}{c}\begin{array}{c}\text { Sample } \\
\text { size }\end{array} \\
416\end{array}$} \\
\hline \multirow{6}{*}{ IB } & 13.5 & & & \multirow{6}{*}{$1 \mathrm{~A}$} & 14 & & \\
\hline & 17 & $>.05$ & 182 & & 15 & $<.001$ & 556 \\
\hline & 19 & $>.05$ & 186 & & 16 & $<.001$ & 118 \\
\hline & 21 & $>.05$ & 120 & & 19 & $<.001$ & 186 \\
\hline & \multirow[t]{2}{*}{25} & $<.001$ & 230 & & 21 & $<.001$ & 94 \\
\hline & & & & & 25 & $<.001$ & 226 \\
\hline \multirow{4}{*}{$2 \mathrm{~B}$} & 14 & $>.05$ & 232 & \multirow{4}{*}{$2 \mathrm{~A}$} & & \multirow{4}{*}{$\begin{array}{l}<.001 \\
<.001\end{array}$} & \multirow{4}{*}{$\begin{array}{l}660 \\
214\end{array}$} \\
\hline & 15 & $>.05$ & 102 & & 14 & & \\
\hline & 20 & $>.05$ & 122 & & 24 & & \\
\hline & 24 & $>.05$ & 228 & & & & \\
\hline \multirow{4}{*}{$1 B_{2}$} & & & & \multirow{4}{*}{$1 B_{3}$} & 4 & $<.001$ & 192 \\
\hline & 4 & $<.05$ & 170 & & 7 & $<.05$ & 186 \\
\hline & 7 & $>.05$ & 130 & & 12 & $<.01$ & 238 \\
\hline & 14 & $<.01$ & 224 & & 17 & $<.01$ & 224 \\
\hline \multirow[b]{3}{*}{$1 B_{t}$} & 4 & $<.01$ & 93 & \multirow[b]{3}{*}{$1 \mathrm{~B}_{4}$} & 4 & $>.05$ & 101 \\
\hline & 7 & $<.001$ & 60 & & 7 & $<.01$ & 104 \\
\hline & 14 & $<.01$ & 113 & & 12 & $<.01$ & 130 \\
\hline \multirow{4}{*}{$1 A_{1}$} & 16 & $<.001$ & 59 & & & & \\
\hline & 19 & $<.001$ & 80 & & & & \\
\hline & 21 & $<.001$ & 145 & \multirow{2}{*}{\multicolumn{2}{|c|}{ m. }} & & \\
\hline & 23 & $<.001$ & 112 & & & & \\
\hline
\end{tabular}


medium". From our findings, it appears that the aforementioned differentiation is dramatic. The observed change in the allozyme frequency of a locus is in a specific direction for all populations studied under similar environmental conditions, thus suggesting the operation of directional selection. Furthermore, by utilizing the allozyme frequencies found in (Greek) natural populations as initial frequencies of the allozymes for the cage populations. we mav assume that a given deviation from the initial (equilibrium) frequencies is due to the parameter under study.

Another factor worthy of consideration and capable of causing differentiation in the variability is genetic drift. In our experiments however, one could argue against genetic drift having played an important role on the basis of the following reasons: 1) large population sizes such that consecutive generations overlapped each other extensively, 2) the findings that changes in gene frequencies under the same environmental conditions were similar in many populations (small differences between populations with different original gene pool may be attributed to different genetic backgrounds), 3) the detection of a reverse frequency differentiation in the $1 A_{1}$ population. 4$)$ the existence of a proportional frequency differentiation in lethal bearing chromosomes (Alahiotis. 1976), and 5 ) in most of the cases our samples for each test were rather large. One cannot rule out the possible effect of genetic drift by the above arguments for the population sizes in poor food medium population were small $(\mathrm{N}=1.100)$. However. the maintainance of high lethal bearing chromosome frequencies $(0.3900-0.4041$ : Alahiotis, 1976) in the same populations suggests the existence of a large Ve (effective populations size). The same is true, at least, in one of the natural populations (Yannopoulos. 1974) from which the founders were captured.

The density achieved by the cage populations studied depends on the type of food medium (poor food medium. high density-rich food medium. low density) used. Competition is one means by which selection can take place. Thus. competition in poor food medium populations must be high, while. it is low in the rich food medium populations. Here, one can only speculate that "mutual facilitation" may be of importance in polymorphic situations (like ours) where the different genotypes segregating in a population could have slightly different ecological requirements, thus resulting in a mutual facilitation (see Parson. 1973. for review). However. more data

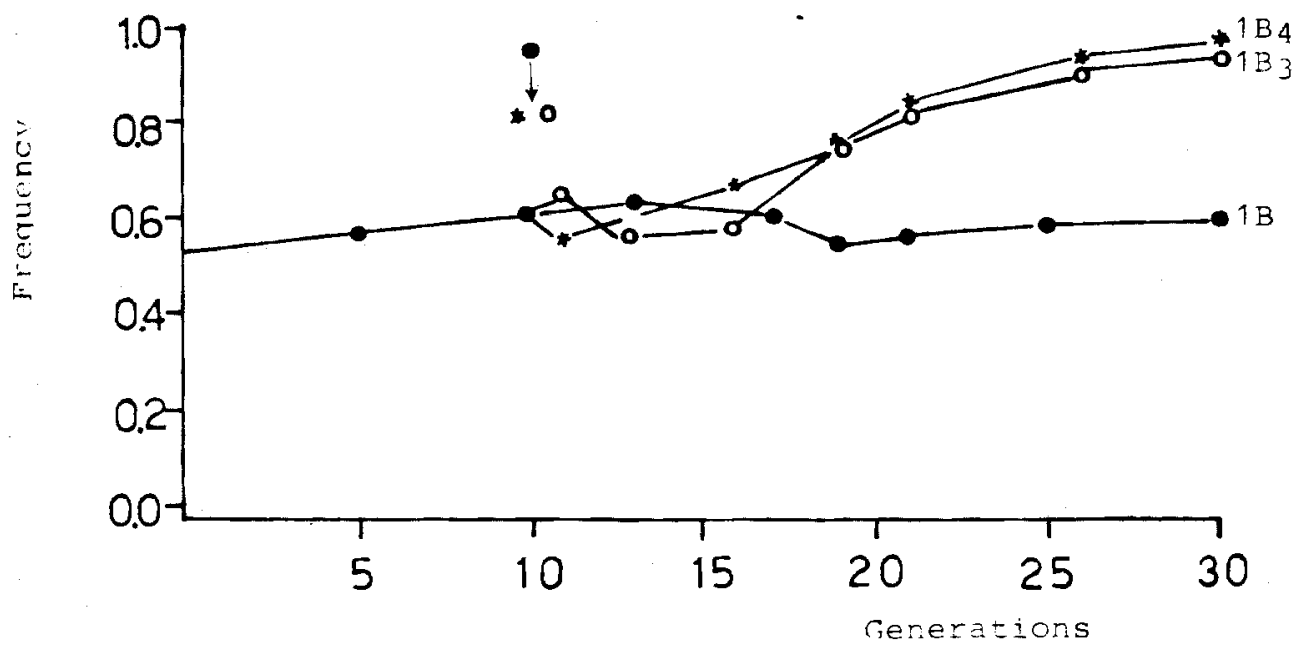

Fig. 3. Changes in frequency of $a \cdot G p d h^{F}$ allele in the $1 \mathrm{~B}, 1,1 \mathrm{~B}_{3}(0), 1 \mathrm{~B}_{4}:$ cage populations, ( $1 \mathrm{~B}_{3}$. 1 $\mathrm{B}_{\mathbf{4}}$-poor food medium: 1 B-rich food medium). 
(e.g. viability experiments) are needed so as to assess whether or not the above situation is true for our populations. It must also be noted that the small amount of live yeast suspension used in the poor medium is consumed by the flies in a few hours so that there is no live yeast left during larval development; hence, we can assume that competition exists for food (yeast) mainly in the larva stage. Thus, the observed dramatic gene pool differentiation could be attributed to the competitive conditions which reflect the difference of the food media. From this point of view it appears that nutrition, and especially yeast, may have some serious effect on gene pool differentiation and ultimately on the evolution of Drosophila melanogaster. It is important to note that we found strong sexual isolation (Isolation Index $\simeq 0.35$ ) in later generations among the same populations.

As already noted, the allozymes at both the $a-G p d h$ and $A d h$ loci are nonrandomly associated with inversions on the second chromosome. The $A d h^{\mathrm{S}}$ and $a-G p d h^{\mathrm{F}}$ alleles are in strong linkage with the $\ln (2 L) 22 D \cdot 34 A$, thus suggesting that the frequency of the $\ln (2 L) 22 D-34 A$ is much higher under competitive conditions than its' standard (see also Alahiotis et al., 1976). These associations do not allow us to attribute the changes in allozyme frequencies to a selective effect at the loci studied. They may very well reflect a process which involves large groups of coadapted genes upon which selection acts (Prakash and Lewontin, 1968, 1971). The proportional frequency differentiation of the lethal bearing chromosomes (Alahiotis, 1976) as well as of the gene arrangements (Alahiotis et al., 1975) and the linkage disequilibrium found between inversions of the second and third chromosomes (Alahiotis et al., 1976) or between the alleles of the two loci studied, favors the above view.

However, in recent studies it has been suggested that allozymes do not constitute part of the coadapted complexes of genes characterizing inversions (Zouros, 1976). Moreover, linkage disequilibrium between allozymes and inversions is considered to be a historical accident where allozymes share their fate with the inversions (Watanabe and Watanabe, 1977). However, by studying additional cage populations (Alahiotis and Pelecanos, 1977) it has been shown that the $a-G p d h$ allele frequencies were found to be

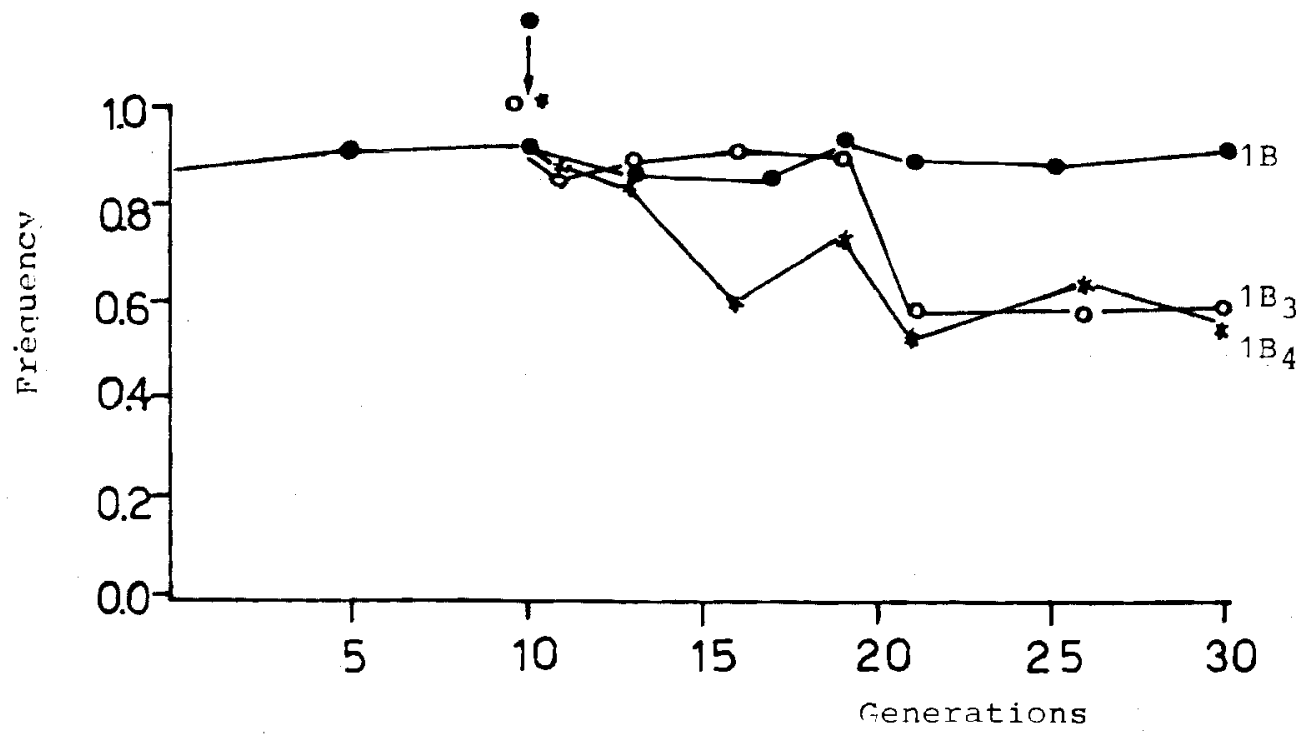

Fig. 4. Changes in frequency of $A d h^{F}$ allele in the $1 \mathrm{~B}(\bullet), 1 \mathrm{~B}_{3}(0), 1 \mathrm{~B}_{4}\left(^{*}\right)$ cage populations, ( $1 B_{3}-1 B_{4}$-poor food medium: 1 B-rich food medium). 
uniform in relation to different second chromosome inversion frequencies $\{\operatorname{In}(2 L) 22 D-34 A\}$, a fact which supports the view that while this locus is included in the inversions. it doesn't share its fate (e.g. in cage populations 1B. $1 D$, natural Greek population (f) $a \cdot G p d h^{\mathrm{F}}=0.6136,0.6293,0.6769$ and (f) $\ln (2 L) 22 D-34 A=0.0611$, $0.4375,0.0462$ respectively). Furthermore, with respect ot the Adh locus, there is similar $A d h$ allele frequency-temperature interaction in populations with low (Natural populations: Pipkin et al, 1976) and high (our cage populations for the temperature effect: Alahiotis and Pelecanos, 1977) second chromosome (2L) inversion frequencies. Finally. since gene frequencies tend to be similar under the same environmental conditions in all cage populations studied, this favors the coadaptation hypothesis.

\section{Acknowledgments}

We are grateful to Drs. E. Berger and S. Miller (Dartmouth College, Department of Biological Sciences, Hanover, New Hampshire, U.S.A.) for helping in the preparation of the manuscript.

\section{References}

Alahiotis, S. 1976. Genetic variation and the ecological parameter "Food medium" in cage populations of Drosophila melanogaster. Can. J. Genet. Cytol. 18: 379-383.

Alahiotis. S., Zacharopoulou, A. and Pelecanos, M. 1975. The effect of two ecological factors upon the inversion frequencies in Drosophila melanogaster cage populations. Dros. Inf. Serv 52.

Alahiotis. S. Pelecanos. M. and Zacharopoulou. A. 1976. A contribution to the study of linkage disequilibrium in Drosophila melanogaster. Can. J. Genet. Cytol. 18: 739-745.

Alahiotis, S. and Pelecanos, M. 1977. The effect of the environmental parameters Temperature and Humidity upon the variability of the gene pool in Drosophila melanogaster. Theoret. Appl. Genet. (submitled for publication).

Demerec. M. 1965. Biology of Drosophila. Hafner Publ. Co.. New York and London.

Johnson. F. M. and Denniston, G. 1964. Genetic variation of Alcohol dehydrogenase in Drosophila melanogaster. Nature (London), 204: 906-907

Kojima. K.. Gillespie, J. and Tobari. Y. N. 1970. A profile of Drosophila species enzyme assayed by electrophoresis I. Number at alleles heterozygoties, and linkage disequilibrium in glucose-metabilizing systems and some other enzymes. Biochem. Genet. 4: 627.

Li. G. G. 1961. Human Genetics. McGraw-Hill, New York.

Nei. M. 1975. Molecular population genetics and evolution, North-Holland Publish. Co., Amsterdam. Oxford.

Parsons. P. A. 1973. Behavioral and ecological genetics. A study in Drosophila. Clarendon Press, Oxford.

Pipkin, S. R.. Franklin-Springer E.. Law, S. and Lubega, S. 1976. New studies of the alcohol dehydrogenase cline in Drosophila melanogaster. J. Hered. 67: 258-266.

Prakash. S. and Lewontin. R. C. 1968. A molecular approach to the study of genic heterozygosity in natural populations. IIl. Direct evidence of coadaptation in gene arrangements of Drosophila. Proc. Natl. Acad. Sci. U.S.A. 59: 398-405

Prakash. S. and Lewontin. R. C. 1971. A molecular approach to the study of genic heterozygosity in natural populations. V. Further direct evidence of coadaptation in inversions of Drosophila. Genetics. 69: $405-408$.

Sang. J, H. 1949. The ecological determinants of population growth in a Drosophila culture. III, Larval and pupae surviva. Physiol. Zool . 22: 183-202.

Shaw, C. R. and Prasad, R. 1970. Starch gel electrophoresis of enzymes. A combination of recipies. Biochem. Genet. 4: 297-320.

Stern, K. 1972. Population cage for long term experiments. Dros. Inf. Serv. $48: 159$.

Watanabe. T. K. and Watanabe, T. 1977. Enzyme and chromosome polymorphisms in Japanese natural populations of Drosophila melanogaster. Genetics, 85: 319-329.

Workman. P. L. and Nisuander, J. D. 1970. Population studies on Southwestem Indian tribes. II. LocaI Generic differentiation in the Papago. Am. J. Hum. Genet. 22: 24-29.

Yannopoulos. G. 1974. A contribution to the study on genetical polymorphism of lethals in a wild Greek Drosophila melanogaster population. Ph. D. Thesis, Univ. Patras, Patras, Greece.

Zouros, E. 1976. The distribution of enzyme and inversion polymorphism over the genome of Drosophila; Evidence against balancing selection. Genetics, 83: 169-179. 